\title{
NON SYNDROMIC APLASIA CUTIS CONGENITA: A CASE REPORT
}

Chandrashekhar $\mathrm{T}^{1}$, Sunita Kittali ${ }^{2}$

\section{HOW TO CITE THIS ARTICLE:}

Chandrashekhar T, Sunita Kittali. "Non Syndromic Aplasia Cutis Congenita: A Case Report". Journal of Evolution of Medical and Dental Sciences 2014; Vol. 3, Issue 48, September 29; Page: 11608-11610,

DOI: $10.14260 /$ jemds/2014/3521

INTRODUCTION: Aplasia Cutis Congenita (ACC) is a rare anomaly characterized by absence of portion of skin over localized or widespread area. ${ }^{1}$ ACC is most often a benign isolated defect, ${ }^{2}$ but it can be associated with other physical anomalies or malformation syndromes. More than 500 cases have been reported since it was first described, due to significant underreporting of this benign disorder, the precise frequency is unknown.

Approximate incidence is $1: 10,000$ births, ${ }^{3}$ with no racial or sexual predilection. Scalp is the commonest location and is involved in almost $85 \%$ of cases rest $15 \%$ cases involve the non-scalp areas like forearms, knees, both sides of the trunk and neck in order of frequency. 4,5

About $15 \%$ to $30 \%$ of the scalp involved patients have skull defects and defects of the dura.

Involved areas are non-inflammatory and well demarcated and vary in size from 0.5 to $10 \mathrm{~cm}$ or larger. At birth lesions may have already healed and appear as an atrophic, membranous, bullous or parchment like scar with associated alopecia or may remain as a superficial lesion or erode deeply and occasionally involve the meninges.

CASE REPORT: G2P1L1 with term pregnancy with previous LSCS (done for CPD) having regular ANC underwent elective LSCS in our hospital. Baby cried immediately after birth on examination we noticed 2 circular ulcerative lesions about $2 * 2.5 \mathrm{~cm}$ and $1 * 1 \mathrm{~cm}$ over the scalp. Base of the ulcer was intact parietal bone. There were no other anomalies. USG of the head was done to rule out any skull defects and defects of dura.

Finally we arrived at the diagnosis of Non-syndromic Aplasia Cutis Congenita. As lesion was superficial it was treated conservatively and the lesions healed almost completely with atrophic scar by the end of three weeks after birth. There was no significant drug history or family history.

DISCUSSION: ACC is an uncommon condition presented at birth. The most common presentation is solitary lesion over the scalp but in our case they are multiple. As for as etiology is concerned it is still not clear. The proposed mechanisms include genetic factors, ${ }^{6}$ teratogens, ${ }^{7}$ (like antithyroid drugs), vascular compromise of the skin and trauma.

Maximum tensile force during the development of scalp hair whorl is implicated for the scalp lesion. Early rupture of amniotic membrane forming amniotic bands may also be responsible ${ }^{8}$.The probability of genetic component is thought because of the occurrence of the condition in family members.

Usually non syndromic ACC has sporadic inheritance and the syndromic ACC has autosomal dominant rarely recessive inheritance. Fridan has provided a classification system for ACC which has nine groups. Classification is based on the number and location of the lesion and modes of inheritance and associated abnormalities. ${ }^{1}$ 
Cutaneous defects noted at birth may be easily confused with obstetric trauma, or from forceps or fetal scalp electrodes. Differential diagnosis includes localized scalp infection, congenital dermoid cyst, small meningocele, heterotopic brain or glial tissue. The main complications of larger defects include infection, bleeding and thrombosis which may lead to death.

Therefore, prompt diagnosis and appropriate treatment are essential to avoid untoward outcomes. Management is either conservative or surgical depending on the extent of the lesions. If the defect is small, recovery is uneventful, with gradual epithelialization and forming hairless, atrophic scar. Small underlying bony defects usually close spontaneously by the end of first year of life.

\section{REFERENCES:}

1. Friedan IJ. Aplasia cutis congenita: a clinical review and proposal for classification. J Am Acad Dermatol 1986; 14: 646-60.

2. Benjamin LT, Trowers AB, Schachner LA. Giant aplasia cutis congenita without associated anomalies. Dermatol 2004; 21: 150-3.

3. Conway H, Johnson G. Congenital absence of scalp: delayed closure complicated by massive hemorrhage. Plast Reconstr surg 1985; 75: 425.

4. Dammel U. Clinical aspects of congenital skin defect. I. Congenital skin defect of head of newborn. Eur J Pediatr 1975; 121: 21-50.

5. Pers M. Congenital Absence of Skin: pathogenesis and relation to ring constriction. Acta Chir Scand 1963; 126; 388-96.

6. Chitnis MR, Carachi R, Galea P. Familial aplasia cutis congenita. Eur J Pediatr Surg 1996; 6: 100-1.

7. Izhar R, Ghani T. Aplasia cutis congenita and antithyroid drugs. J Pak Med Assoc 2002; 52: 526-8.

8. Mark. A Crowe, Aplasia Cutis Congenita. Section 2-9, e-medicine.com.inc. 2004.

Fig. 1: Ulcerative (ACC) lesions over the Scalp at birth.

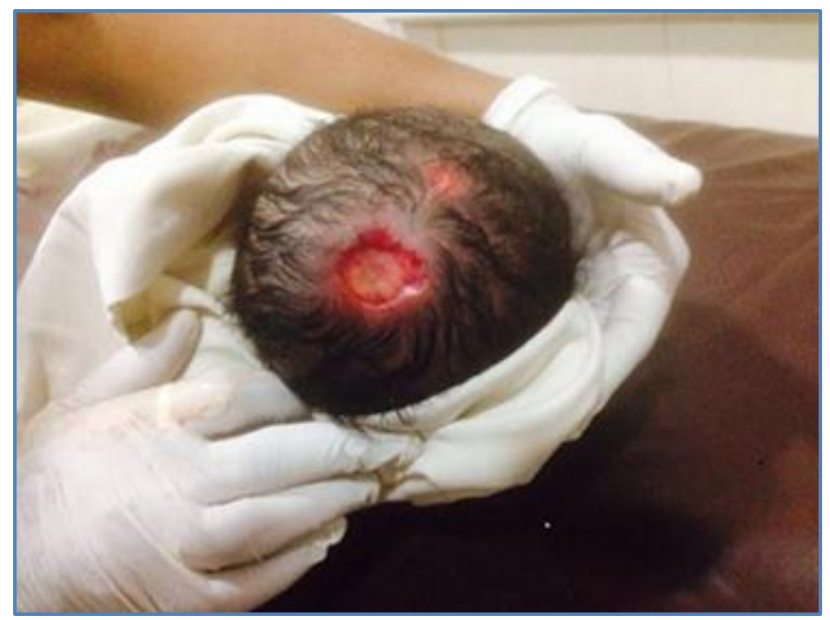

Fig. 1 


\section{CASE REPORT}

Fig. 2: Healed scars of the lesions after 3 weeks.

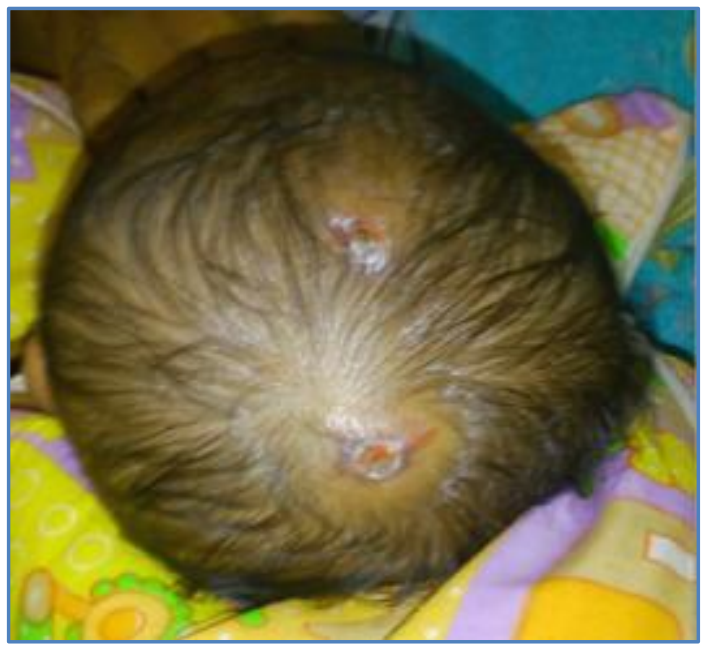

Fig. 2

\section{AUTHORS:}

1. Chandrashekhar T.

2. Sunita Kittali

\section{PARTICULARS OF CONTRIBUTORS:}

1. Associate Professor, Department of Obstetrics and Gynaecology, VIMS, Bellary.

2. Junior Resident, Department of Obstetrics and Gynaecology, VIMS, Bellary.

\section{NAME ADDRESS EMAIL ID OF THE} CORRESPONDING AUTHOR:

Dr. Chandrashekhar T,

Associate Professor,

Department of Obstetrics and Gynecology, VIMS, Bellary, Karnataka.

Email: cstobg@gmail.com

Date of Submission: 12/09/2014.

Date of Peer Review: 13/09/2014.

Date of Acceptance: 19/09/2014.

Date of Publishing: 29/09/2014. 